\title{
Cancer Screening Among Women Prescribed Opioids: A National Study
}

\author{
Alicia Agnoli, MD, MPH, MHS \\ Anthony Jerant, MD \\ Peter Franks, MD
}

Department of Family and Community Medicine, University of California, Davis, School of Medicine, Sacramento, California

Conflicts of interest: authors report none.

\section{CORRESPONDING AUTHOR}

Alicia Agnoli, MD, MPH, MHS Department of Family and Community Medicine

UC Davis School of Medicine 4860 Y Street, Suite 2300

Sacramento, CA 95817

aagnoli@ucdavis.edu

\begin{abstract}
PURPOSE Prior work suggests that there are competing demands between addressing pain and other issues in primary care, potentially lessening delivery of evidence-based cancer screening. We assessed the association between opioid therapy and cancer screening among women in a nationally representative US sample.
\end{abstract}

METHODS We conducted an observational analysis of the 2005-2015 Medical Expenditure Panel Surveys. We included all women aged $\geq 18$ years without cancer and with opioid prescription and preventive care services data. Logistic regression analyses examined associations between receipt of opioid prescription (any vs none) and receipt of breast, cervical, and colorectal cancer screenings. Analyses were adjusted for sociodemographic characteristics, health status, health conditions, and usual source of care, as well as health care utilization.

RESULTS Of 53,982 participants, $15.8 \%$ reported $\geq 1$ opioid prescription. Compared with women not prescribed opioids, those prescribed opioids were more likely to visit their doctor (median number of visits per year $=5$, vs 1 ). Without adjustment for number of visits, women prescribed opioids were more likely to receive all 3 cancer screenings; the adjusted odds ratio for breast cancer screening was $1.26(95 \% \mathrm{Cl}, 1.16-1.38)$, that for cervical cancer screening was 1.22 $(95 \% \mathrm{Cl}, 1.13-1.33)$, and that for colorectal cancer screening was $1.22(95 \% \mathrm{Cl}$, 1.12-1.33). With adjustment for number of visits, adjusted odds ratios decreased (breast 1.07 [95\% Cl, 0.98-1.18]; cervical 1.01 [95\% Cl, 0.93-1.09]; colorectal 1.04 [95\% Cl, 0.95-1.14]).

CONCLUSIONS In a nationally representative sample, receipt of opioid prescriptions was not associated with less recommended cancer screenings. Rather, women receiving opioids had greater adjusted odds of receiving breast, cervical, and colorectal cancer screening, although the associations were attenuated by adjusting for their more frequent office visits relative to women not receiving opioids.

Ann Fam Med 2020;18:59-65. https://doi.org/10.1370/afm.2489.

\section{INTRODUCTION}

A mid the ongoing epidemic of opioid-related mortality and morbidity, the use of prescription opioid therapy has been increasingly scrutinized. Studies have consistently shown associations between prescription opioids and specific poor health outcomes such as opioid use disorder and overdose ${ }_{1}^{1-4}$ as well as disability. ${ }^{5,6}$ By contrast, evidence of the effects of prescribed opioids on health-related behaviors remains conflicting ${ }^{7,8}$ suggesting that this is a potentially complex relation.

Concerns have been raised that in the primary care setting, treating chronic pain and managing opioid prescriptions might be associated with negative preventive care outcomes. ${ }^{9-11}$ Managing patient pain and prescription opioids takes considerable time and can strain the patient-physician relationship..$^{12}$ In addition, primary care physicians are not traditionally trained to identify addiction, resulting in added discomfort in managing opioids. ${ }^{13}$ Given the known competing demands in primary care, ${ }^{14,15}$ these additional strains might impair the delivery of evidence-based preventive health care such as recommended cancer screenings. One study showed 
that certain preventive services were less likely to be delivered among opioid-prescribed individuals compared to others ${ }^{16}{ }_{i}$ however, this relation has not been examined in large studies of nationally representative samples of individuals.

The potential for reduced preventive care delivery in the context of prescription opioid use might be greatest among women because they are more likely than men to experience chronic pain, receive prescription opioid therapy, be prescribed high doses of opioids, and continue use for longer periods of time. ${ }^{17,18}$ We sought to assess the relation between opioid prescriptions and cancer screenings among women in a large, nationally representative US sample. We also examined how the relation between opioid prescriptions and cancer screening might be affected by health care utilization.

\section{METHODS}

\section{Data Source}

The Medical Expenditure Panel Survey (MEPS) is a nationally representative survey of health care use and costs in the US civilian, noninstitutionalized population. The survey is conducted by the Agency for Healthcare Research and Quality as a subset of the National Health Interview Survey and uses an overlapping panel design. Data are collected for each enrollee over 2 consecutive years via baseline and follow-up interviews. ${ }^{19}$ The MEPS Household Component collects information on interview language, country of origin, sociodemographic information, usual source of care, and health insurance coverage, as well as information on preventive care utilization (including most recent cancer screening). The following 2 survey components were also examined. The MEPS Prescribed Medicines file is a subcomponent detailing prescription drug information for all survey participants during each of the follow-up interviews. The MEPS Medical Conditions file documents all conditions reported by respondents at each follow-up survey. We used data from these 3 components for the years 2005-2015, the most recent decade of available data at the time of this analysis. Response rates decreased from $61.3 \%$ to $47.7 \%$ during the study years. ${ }^{20}$

The analytic sample for this study included all women participants aged $\geq 18$ years who provided baseline data and for whom data on prescriptions and preventive care services were available within the first of their 2 study participation years. Women with a diagnosis of cancer were excluded from the analysis. We used a cross-sectional analysis to assess the associations between exposure to opioid prescriptions and other patient factors (sociodemographic characteristics, markers of health status, and health care utiliza- tion) and receipt of screening for breast, cervical, and colorectal cancers. This study was deemed exempt from review by the University of California Davis Institutional Review Board.

\section{Measures}

\section{Opioid Prescriptions}

We categorized prescription opioid exposure using the number of discrete opioid prescriptions reported in the Prescribed Medicines file, which has been used previously to examine prescription opioid exposure. ${ }^{21,22}$ Opioid prescriptions were categorized as none or any $(\geq 1)$ reported. Additional sensitivity analyses were conducted using different categories of opioid prescriptions, including 6 or more prescriptions in the year (defining chronic use) compared to no exposure, and separately using different strata of opioid prescriptions $(0,1,2-3,4-11$, or $\geq 12$ prescriptions), chosen to represent minimal exposure (1 prescription), short exposure (2-3 prescriptions), longer-term use (4-11 prescriptions), and continuous use ( $\geq 12$ prescriptions).

\section{Measures}

We looked at 3 key cancer screenings for women, based approximately on the recommendations from the United States Preventive Services Task Force. ${ }^{23}$ We defined breast cancer screening as reporting a mammogram within the past 2 years if aged $>40$ years during survey participation. Cervical cancer screening was defined as reporting a Papanicolaou (Pap) test within the past 3 years. Colorectal cancer screening was coded for women aged $\geq 50$ years if they reported a fecal occult blood screening test within the past 2 years, flexible sigmoidoscopy within 5 years of the survey, or colonoscopy within 10 years of the survey.

\section{Covariates}

We included key variables to account for sociodemographic characteristics, health status, health behaviors, and health care utilization, all selected on the basis of prior work showing association with receipt of preventive care. ${ }^{24-26}$ Sociodemographic covariates included age (years), self-reported race/ethnicity (white [nonHispanic], Hispanic, black [non-Hispanic], other), US census region (Northeast, Midwest, South, West), education level (less than high school, some high school, high school graduate, some college, college graduate), household income (<100\%, 100\%-124\%, 125\%-199\%, $200 \%-399 \%$, or $\geq 400 \%$ of the federal poverty level), and health insurance status (uninsured, any private insurance, public insurance alone). Measures of health status included the 12-Item Short-Form Health Survey, both the Mental Component Summary and Physical Component Summary scores. Separately, we assessed 
responses to the single question, "In general, would you say your health is: excellent, very good, good, fair, or poor?"27,28 We further assessed morbidity using a count of 8 self-reported chronic conditions (diabetes, hypertension, coronary heart disease, myocardial infarction, cerebrovascular disease, asthma, emphysema, and arthritis). Self-reported smoking status (nonsmoker vs current smoker) and reporting a usual source of health care (yes/no response to the question, "Is there a particular doctor's office, clinic, health center, or other place that the individual usually goes to if he/she is sick or needs advice about his/her health?") were also included. To measure health care utilization, a potential marker for morbidity as well as propensity to seek care, we included a variable for total number of physician office visits in year 1 .

\section{Statistical Analyses}

We analyzed data using Stata version 15.1 (StataCorp LLC). In the reported descriptive analyses, no survey adjustments were made. For all regression analyses, we used longitudinal strata and primary sampling unit identifiers, with survey weights to account for the complex survey design and sampling design of successive waves of the MEPS. We performed a sequence of logistic regression analyses to assess the association between opioid prescription and receipt of each cancer screening. To test the proposed relation between greater health care utilization and receiving cancer screenings, we modeled each cancer screening separately, without and then with the utilization variable. We assessed each of these paired models using adjusted Wald tests to compare the parameter estimates.

For all models, the key independent variable was receipt of opioid prescription, assessed as none vs any received. All analyses also adjusted for MEPS panel year to account for potential secular temporal trends. To examine the potential differential effects of greater opioid use, we performed sensitivity analyses assessing different categories of prescription opioid exposure (as described above).

\section{RESULTS}

The analytic sample included 53,982 female MEPS participants for the time period 2005-2015 with complete baseline and health data and cancer screening reports. We excluded 18,654 women who had a prior diagnosis of cancer $(n=2,547)$ or were missing $\geq 1$ variable $(n=16,107)$. Table 1 summarizes the characteristics of the analytic sample, comparing those reporting any opioid prescription with those reporting none. In total, $15.8 \%$ of the sample reported $\geq 1$ opioid pre-

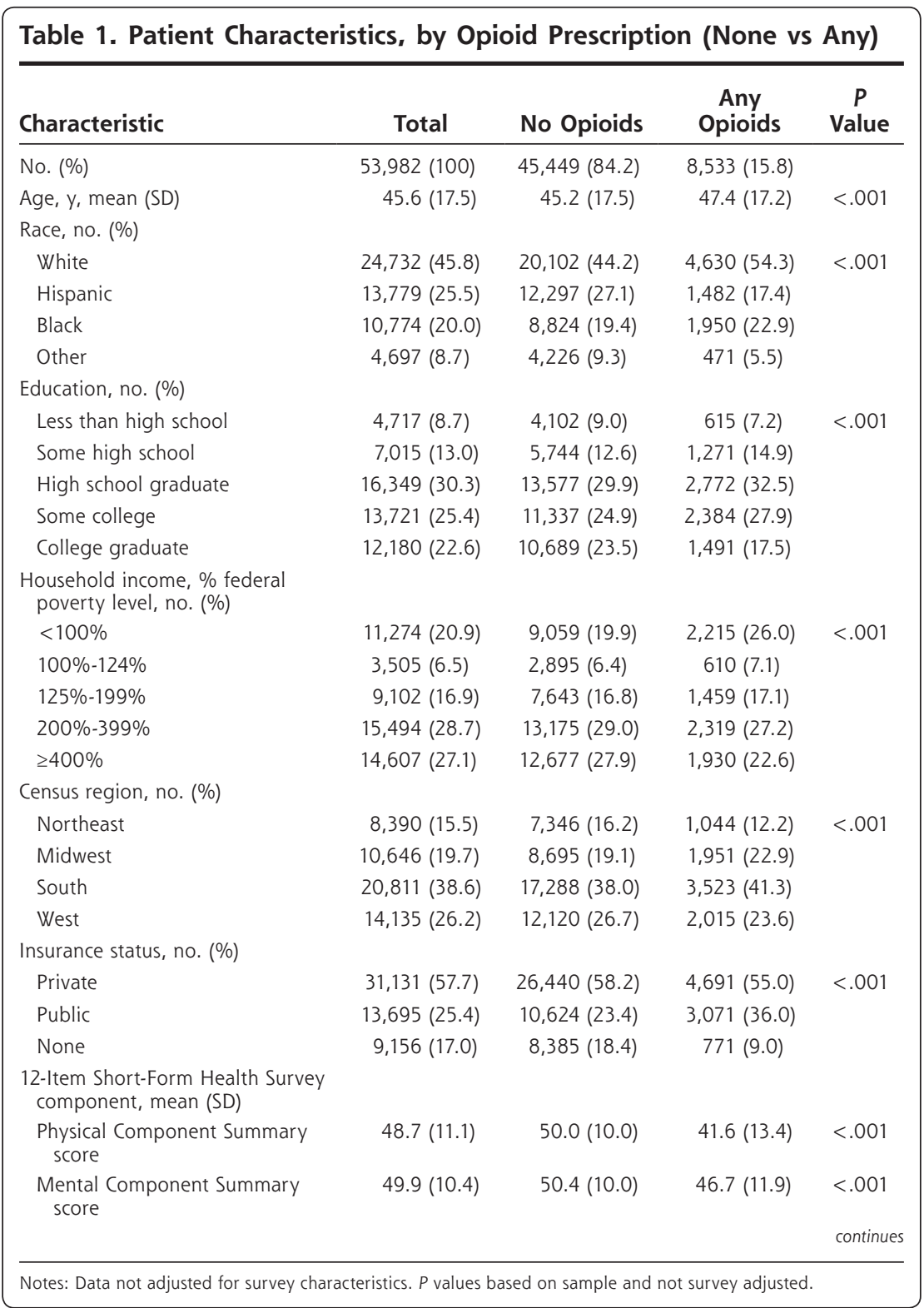




\begin{tabular}{|c|c|c|c|c|}
\hline Characteristic & Total & No Opioids & $\begin{array}{l}\text { Any } \\
\text { Opioids }\end{array}$ & $\begin{array}{c}P \\
\text { Value }\end{array}$ \\
\hline \multicolumn{5}{|l|}{ Self-rated health, no. (\%) } \\
\hline Excellent & $11,481(21.3)$ & $10,508(23.1)$ & $973(11.4)$ & \multirow[t]{5}{*}{$<.001$} \\
\hline Very good & $17,285(32.0)$ & $15,265(33.6)$ & $2,020(23.7)$ & \\
\hline Good & $16,309(30.2)$ & $13,541(29.8)$ & $2,768(32.4)$ & \\
\hline Fair & $6,948(12.9)$ & $5,079(11.2)$ & $1,869(21.9)$ & \\
\hline Poor & $1,959(3.6)$ & $1,056(2.3)$ & $903(10.6)$ & \\
\hline \multicolumn{5}{|l|}{ Current smoker, no. (\%) } \\
\hline No & $45,543(84.4)$ & $39,127(86.1)$ & $6,416(75.2)$ & \multirow[t]{2}{*}{$<.001$} \\
\hline Yes & $8,439(15.6)$ & $6,322(13.9)$ & $2,117(24.8)$ & \\
\hline $\begin{array}{l}\text { Count of chronic diseases, } \\
\text { median (IQR) }\end{array}$ & $\begin{array}{r}0 \\
(0-1.0)\end{array}$ & $\begin{array}{r}0 \\
(0-1.0)\end{array}$ & $\begin{array}{r}1.0 \\
(0-2.0)\end{array}$ & $<.001$ \\
\hline \multicolumn{5}{|l|}{ Usual source of care, no. (\%) } \\
\hline No & $12,534(23.2)$ & $11,337(24.9)$ & $1,197(14.0)$ & \multirow[t]{2}{*}{$<.001$} \\
\hline Yes & $41,448(76.8)$ & $34,112(75.1)$ & $7,336(86.0)$ & \\
\hline $\begin{array}{l}\text { Number of office visits, } \\
\text { median (IQR) }\end{array}$ & $\begin{array}{r}2.0 \\
(0-5.0)\end{array}$ & $\begin{array}{r}1.0 \\
(0-4.0)\end{array}$ & $\begin{array}{c}5.0 \\
(2.0-10.0)\end{array}$ & $<.001$ \\
\hline \multicolumn{5}{|l|}{ Opioid category, no. (\%) } \\
\hline 0 prescriptions & $45,449(84.2)$ & $45,449(100.0)$ & $\ldots$ & \multirow[t]{5}{*}{$<.001$} \\
\hline 1 prescription & $4,505(8.3)$ & $\ldots$ & $4,505(52.8)$ & \\
\hline $2-3$ prescriptions & $1,779(3.3)$ & $\ldots$ & $1,779(20.8)$ & \\
\hline 4-11 prescriptions & $1,622(3.0)$ & $\ldots$ & $1,622(19.0)$ & \\
\hline$\geq 12$ prescriptions & $627(1.2)$ & $\ldots$ & $627(7.3)$ & \\
\hline \multicolumn{5}{|c|}{ Cervical cancer screening, no. (\%) } \\
\hline Yes & $39,229(84.2)$ & $32,914(84.1)$ & $6,315(84.8)$ & .13 \\
\hline \multicolumn{5}{|c|}{ Breast cancer screening, no. (\%) } \\
\hline Yes & $23,449(70.7)$ & $19,220(70.2)$ & $4,229(73.2)$ & $<.001$ \\
\hline \multicolumn{5}{|l|}{$\begin{array}{l}\text { Colorectal cancer screening, } \\
\text { no. }(\%)\end{array}$} \\
\hline Yes & $11,622(49.2)$ & $9,276(47.8)$ & $2,346(55.8)$ & $<.001$ \\
\hline
\end{tabular}

lived outside the Northeast, had insurance, worse SF 12 scores, worse self-rated health, smoked, had more chronic diseases, reported a usual source of care, and reported more office visits.

Table 3 shows the adjusted odds ratios for breast, cervical, and colorectal cancer screenings, comparing logistic regression models that exclude and include total doctor's office visits. Without accounting for their greater rates of utilization (Model 1), women who received opioids had greater adjusted odds ratios (AORs) for breast cancer screening $(\mathrm{AOR}=1.26$; 95\% CI, 1.161.38), cervical cancer screening $(\mathrm{AOR}=1.22 ; 95 \% \mathrm{CI}, 1.13-1.33)$, and colorectal cancer screening $(\mathrm{AOR}=1.22 ; 95 \% \mathrm{CI}, 1.12-1.33)$ compared to women who did not receive opioids. Model 2 included adjustment for utilization (measured by total doctor's office visits) and showed a decrease in AORs for all 3 screening tests: breast cancer screening $(\mathrm{AOR}=1.07 ; 95 \%$ CI, 0.98-1.18), cervical cancer screening $(\mathrm{AOR}=1.01 ; 95 \% \mathrm{CI}$, 0.93-1.09), and colorectal cancer screening $(\mathrm{AOR}=1.04 ; 95 \% \mathrm{CI}$,

scription. The majority (52.8\%) of opioid-prescribed respondents reported only 1 prescription; $26.3 \%$ reported $\geq 4$ prescriptions. Compared to women who did not receive opioids, women who received opioids were more likely to be older, white, of lower income, live in the Midwest and South census regions, and have public insurance. They were also more likely to have poor health status, with lower mean Physical Component Summary and Mental Component Summary scores, poorer self-rated health, and greater rates of smoking, and also more frequently reporting a usual source of care. Women receiving opioids had greater rates of health care utilization (more office visits).

Table 2 shows the adjusted odds of reporting opioid prescriptions, by patient characteristic. In the adjusted model, women were more likely to report opioids if they were younger, had intermediate levels of education (between some high school and some college), had income $<200 \%$ of the federal poverty level,
$0.95-1.14)$. The parameter estimates for the 2 models (with and without utilization) for each cancer screening were compared using adjusted Wald tests. For each of these comparisons, the attenuation with adjustment for utilization was statistically significant (all $P$ values $<.001$ ). Analyses using various categories of opioid prescriptions yielded similar results (detailed findings available from the authors).

\section{DISCUSSION}

The findings of the present study show that women who receive opioid prescriptions are no less likely to report undergoing recommended cancer screenings than those who do not receive such prescriptions. In models that did not account for their greater health care utilization, the results suggested a greater likelihood of breast, cervical, and colorectal cancer screenings among women prescribed opioids compared to women 
who were not. Adjusting for total doctor's office visits showed attenuation of this effect. These fully adjusted models showed little relation between opioids and cancer screenings. This suggests that the key driver of

\section{Table 2. Adjusted Odds of Reporting Opioid Prescriptions, by Patient Characteristic}

\begin{tabular}{|c|c|c|}
\hline Characteristic & AOR $(95 \% \mathrm{Cl})$ & $P$ Value \\
\hline Age & $0.98(0.98-0.98)$ & $<.001$ \\
\hline \multicolumn{3}{|l|}{ Race/ethnicity (ref = white) } \\
\hline Hispanic & $0.67(0.61-0.73)$ & $<.001$ \\
\hline Black & $0.91(0.84-0.99)$ & .023 \\
\hline Other & $0.6(0.52-0.69)$ & $<.001$ \\
\hline \multicolumn{3}{|l|}{ Education (ref = less than high school) } \\
\hline Some high school & $1.18(1.02-1.36)$ & .028 \\
\hline High school graduate & $1.21(1.05-1.39)$ & .008 \\
\hline Some college & $1.29(1.12-1.47)$ & $<.001$ \\
\hline College graduate & $1.08(0.93-1.25)$ & .299 \\
\hline \multicolumn{3}{|l|}{$\begin{array}{l}\text { Household income, \% federal poverty } \\
\text { level (ref }=<100 \%)\end{array}$} \\
\hline $100 \%-124 \%$ & $0.97(0.84-1.11)$ & .643 \\
\hline $125 \%-199 \%$ & $0.96(0.87-1.05)$ & .332 \\
\hline $200 \%-399 \%$ & $0.88(0.8-0.97)$ & .014 \\
\hline$\geq 400 \%$ & $0.84(0.75-0.94)$ & .003 \\
\hline \multicolumn{3}{|l|}{ Census region (ref $=$ Northeast) } \\
\hline Midwest & $1.59(1.43-1.77)$ & $<.001$ \\
\hline South & $1.58(1.42-1.76)$ & $<.001$ \\
\hline West & $1.7(1.52-1.9)$ & $<.001$ \\
\hline \multicolumn{3}{|l|}{ Insurance status (ref = private) } \\
\hline Public & $0.95(0.87-1.03)$ & .206 \\
\hline None & $0.59(0.53-0.67)$ & $<.001$ \\
\hline \multicolumn{3}{|l|}{$\begin{array}{l}\text { 12-Item Short-Form Health Survey } \\
\text { component }\end{array}$} \\
\hline Physical Component Summary score & $0.95(0.95-0.96)$ & $<.001$ \\
\hline Mental Component Summary score & $0.99(0.98-0.99)$ & $<.001$ \\
\hline Self-rated health & $1.07(1.03-1.11)$ & .001 \\
\hline Current smoker (vs nonsmoker) & $1.56(1.45-1.67)$ & $<.001$ \\
\hline Count of chronic diseases & $1.05(1.02-1.09)$ & .001 \\
\hline Usual source of care, Yes (vs No) & $1.43(1.31-1.56)$ & $<.001$ \\
\hline Number of office visits & $1.08(1.07-1.08)$ & $<.001$ \\
\hline
\end{tabular}

whether women receive recommended cancer screenings is simply how often they see their doctor.

The opioid-preventive care relation was consistent in sensitivity analyses that examined different categories of opioid prescription use. These findings counter prevailing concerns that addressing pain and managing prescription opioid therapy might be detrimental to achieving preventive health goals because the need to address opioid-related issues creates competing demands for clinicians and patients. ${ }^{29-32}$ Despite prior suggestions of primary care opportunity costs, as well as potentially strained doctor-patient relationships in relation to opioids, our analyses failed to show such adverse effects. Whereas a prior study found lower odds of preventive care among patients on long-term opioid therapy ${ }_{1}^{16}$ we suspect that difference was due to their much earlier analysis being performed with a smaller, selected, regional sample. On the basis of the findings of our national analysis, we speculate that the more frequent visits associated with chronic pain treatment and longterm opioid therapy may represent an opportunity for a stronger doctor-patient relationship, with greater trust and more chances to address preventive health needs.

The findings of the present study must be interpreted with certain limitations in mind. Although we propose a mechanism by which women receiving opioid prescriptions are more likely to undergo recommended cancer screenings, we are limited in what we can interpret regarding the potentially complex pathways that lead women to complete these tests. This was an observational study that may have unmeasured confounding. In addition, all measures were selfreported and are imprecise measures of actual screening received. Furthermore, the measures for cancer screenings are based on evidence-based recommendations, but they do not perfectly match current United States Preventive Services

Table 3. Adjusted Odds of Cancer Screening, Without and With Health Care Utilization Adjustment

\begin{tabular}{|c|c|c|c|}
\hline Screening Test & $\begin{array}{l}\text { Model 1: Without Utilization } \\
\text { Adjustment, AOR ( } 95 \% \mathrm{CI})\end{array}$ & $\begin{array}{l}\text { Model 2: With Utilization } \\
\text { Adjustment, AOR (95\% CI) }\end{array}$ & $\begin{array}{c}\text { Statistical Significance of } \\
\text { Difference Between Models } \\
(P \text { Value })^{a}\end{array}$ \\
\hline Breast cancer $(n=33,166)$ & $1.26(1.16-1.38) P<.001$ & $1.07(0.98-1.18) P=.09$ & $<.001$ \\
\hline Cervical cancer $(n=46,598)$ & $1.22(1.13-1.33) P<.001$ & $1.01(0.93-1.09) P=.8$ & $<.001$ \\
\hline Colorectal cancer $(n=23,613)$ & $1.22(1.12-1.33) P<.001$ & $1.04(0.95-1.14) P=.35$ & $<.001$ \\
\hline
\end{tabular}


Task Force cancer screening guidelines, owing to limitations in the data and changes to recommended practice during the study period. The analysis may also have been limited by missing observations (nonresponse as well as missing variables), which may limit generalizability. However, despite these limitations, the present results suggest an important contradiction to the presumption that opioids are universally disadvantageous to health outcomes.

Our findings are particularly relevant because physicians have grown increasingly wary of prescription opioids. With so many competing demands and fears of addiction or overdose, primary care physicians might be tempted to avoid opioid prescribing altogether. However, our findings suggest that such an approach might not optimize preventive care outcomes. With ongoing increases in opioid-related mortality $^{33}$ despite decreasing opioid prescribing, ${ }^{34}$ a more nuanced understanding of individualized risks related to opioids is ever more necessary. In addition, by examining more closely the relation between opioids and preventive care outcomes, future work could elucidate factors about primary care relations associated with improved safety for opioid-prescribed individuals.

In conclusion, in this nationally representative sample during the years 2005-2015, women who received opioids were no less likely to undergo recommended cancer screenings but conversely, had greater rates of these tests. These greater rates of preventive care appear to be related to greater rates of doctor's visits. Although there may be other key health risks posed by opioid therapy (not examined here), ${ }^{35,36}$ prescription opioids do not appear to adversely affect the delivery of the evidence-based cancer screenings that we examined.

To read or post commentaries in response to this article, see it online at http://www.AnnFamMed.org/content/18/1/59.

Submitted February 1, 2019; submitted, revised, June 19, 2019; accepted July 17, 2019.

Key words: opioids; women's health; cancer screening

Funding support: Dr Agnoli's work on this project was supported by the Dean's Scholar in Women's Health Research career development award, funded by the University of California Davis School of Medicine Dean's Office.

\section{References}

1. Bohnert AS, Valenstein M, Bair MJ, et al. Association between opioid prescribing patterns and opioid overdose-related deaths. JAMA. 2011;305(13):1315-1321.

2. Brat GA, Agniel D, Beam A, et al. Postsurgical prescriptions for opioid naive patients and association with overdose and misuse: retrospective cohort study. BMJ. 2018;360:j5790.
3. Dunn KM, Saunders KW, Rutter CM, et al. Opioid prescriptions for chronic pain and overdose: a cohort study. Ann Intern Med. 2010; 152(2):85-92.

4. Edlund MJ, Martin BC, Russo JE, DeVries A, Braden JB, Sullivan MD. The role of opioid prescription in incident opioid abuse and dependence among individuals with chronic noncancer pain: the role of opioid prescription. Clin J Pain. 2014;30(7):557-564.

5. Ashworth J, Green DJ, Dunn KM, Jordan KP. Opioid use among low back pain patients in primary care: is opioid prescription associated with disability at 6-month follow-up? Pain. 2013;154(7):1038-1044.

6. Sites BD, Beach ML, Davis MA. Increases in the use of prescription opioid analgesics and the lack of improvement in disability metrics among users. Reg Anesth Pain Med. 2014;39(1):6-12.

7. Dillie KS, Fleming MF, Mundt MP, French MT. Quality of life associated with daily opioid therapy in a primary care chronic pain sample. J Am Board Fam Med. 2008;21(2):108-117.

8. Devulder J, Richarz U, Nataraja SH. Impact of long-term use of opioids on quality of life in patients with chronic, non-malignant pain. Curr Med Res Opin. 2005;21(10):1555-1568.

9. Reid MC, Engles-Horton LL, Weber MB, Kerns RD, Rogers EL, O'Connor PG. Use of opioid medications for chronic noncancer pain syndromes in primary care. J Gen Intern Med. 2002;17(3):173-179.

10. Blyth FM, March LM, Brnabic AJ, Cousins MJ. Chronic pain and frequent use of health care. Pain. 2004;111(1-2):51-58.

11. Darnall BD, Stacey BR, Chou R. Medical and psychological risks and consequences of long-term opioid therapy in women. Pain Med. 2012;13(9):1181-1211.

12. Bertakis KD, Azari R, Callahan EJ. Patient pain: its influence on primary care physician-patient interaction. Fam Med. 2003;35(2): 119-123.

13. Miller NS, Sheppard LM, Colenda CC, Magen J. Why physicians are unprepared to treat patients who have alcohol- and drug-related disorders. Acad Med. 2001;76(5):410-418.

14. Yarnall KS, Pollak KI, Østbye T, Krause KM, Michener JL. Primary care: is there enough time for prevention? Am J Public Health. 2003; 93(4):635-641.

15. Korownyk C, McCormack J, Kolber MR, Garrison S, Allan GM. Competing demands and opportunities in primary care. Can Fam Physician. 2017;63(9):664-668.

16. Buckley DI, Calvert JF, Lapidus JA, Morris CD. Chronic opioid therapy and preventive services in rural primary care: an Oregon rural practice-based research network study. Ann Fam Med. 2010;8(3):237-244.

17. Serdarevic M, Striley CW, Cottler LB. Sex differences in prescription opioid use. Curr Opin Psychiatry. 2017;30(4):238-246.

18. Shah A, Hayes CJ, Martin BC. Characteristics of initial prescription episodes and likelihood of long-term opioid use - United States, 2006-2015. MMWR Morb Mortal W/kly Rep. 2017;66(10):265-269.

19. US Department of Health and Human Services. Agency for Healthcare Research and Quality. Medical Expenditure Panel Survey - survey background. https://meps.ahrq.gov/mepsweb/about_meps/ survey_back.jsp. Accessed Nov 7, 2019.

20. US Department of Health and Human Services. Agency for Healthcare Research and Quality. Medical Expenditure Panel Survey: MEPS-HC response rates by panel. https://meps.ahrq.gov/survey_ comp/hc_response_rate.jsp. Accessed Nov 7, 2019.

21. Sites BD, Harrison J, Herrick MD, Masaracchia MM, Beach ML, Davis MA. Prescription opioid use and satisfaction with care among adults with musculoskeletal conditions. Ann Fam Med. 2018;16(1):6-13.

22. Qureshi ZP, Haider MR, Rodriguez-Monguio R, et al. Opioid prescription drug use and expenditures in US outpatient physician offices: evidence from two nationally representative surveys. Cancer Ther Oncol Int J. 2017;3(3):555611. 
23. US Preventive Services Task Force. USPSTF A and B Recommendations. https://www.uspreventiveservicestaskforce.org/Page/Name/ uspstf-a-and-b-recommendations/. Published Nov 2018. Accessed Nov 7, 2019.

24. VanGompel EC, Jerant AF, Franks P. Primary care attributes associated with receipt of preventive care services: a national study. J Am Board Fam Med. 2015;28(6):733-741.

25. Sambamoorthi U, McAlpine DD. Racial, ethnic, socioeconomic, and access disparities in the use of preventive services among women. Prev Med. 2003;37(5):475-484.

26. Holden CD, Chen J, Dagher RK. Preventive care utilization among the uninsured by race/ethnicity and income. Am J Prev Med. 2015; 48(1):13-21.

27. DeSalvo KB, Fan VS, McDonell MB, Fihn SD. Predicting mortality and healthcare utilization with a single question. Health Serv Res. 2005;40(4):1234-1246.

28. DeSalvo KB, Bloser N, Reynolds K, He J, Muntner P. Mortality prediction with a single general self-rated health question. A metaanalysis. J Gen Intern Med. 2006;21(3):267-275.

29. Jaén CR, Stange KC, Nutting PA. Competing demands of primary care: a model for the delivery of clinical preventive services. J Fam Pract. 1994;38(2):166-171.
30. Bergman AA, Matthias MS, Coffing JM, Krebs EE. Contrasting tensions between patients and PCPs in chronic pain management: a qualitative study. Pain Med. 2013;14(11):1689-1697.

31. Matthias MS, Parpart AL, Nyland KA, et al. The patient-provider relationship in chronic pain care: providers' perspectives. Pain Med. 2010;11(11):1688-1697.

32. Abbo ED, Zhang Q, Zelder M, Huang ES. The increasing number of clinical items addressed during the time of adult primary care visits. J Gen Intern Med. 2008;23(12):2058-2065.

33. Rudd RA, Seth P, David F, Scholl L. Increases in drug and opioidinvolved overdose deaths - United States, 2010-2015. MMWR Morb Mortal Wkly Rep. 2016;65(50-51):1445-1452.

34. Guy GP Jr, Zhang K, Bohm MK, et al. Vital signs: changes in opioid prescribing in the United States, 2006-2015. MMWR Morb Mortal Wkly Rep. 2017;66(26):697-704.

35. Noble M, Treadwell JR, Tregear SJ, et al. Long-term opioid management for chronic noncancer pain. Cochrane Database Syst Rev. 2010;(1):CD006605.

36. Els C, Jackson TD, Kunyk D, et al. Adverse events associated with medium- and long-term use of opioids for chronic non-cancer pain: an overview of Cochrane Reviews. Cochrane Database Syst Rev. 2017; 10:CD012509.

\section{CHANGE-OF-ADDRESS FORM \\ FAMNILY MEDICINE}

Please complete this form and mail to the following address or fax to Annals Circulation at 913-906-6080:

Annals of Family Medicine, Circulation Department, 11400 Tomahawk Creek Pkwy, Leawood, KS 66211-2680
Check if member of sponsoring organization: $\square$ AAFP $\square$ ABFM $\square$ STFM $\square$ ADFM
$\square$ AFMRD $\square$ NAPCRG $\square$ CFPC

ID number from label on your journal cover

OLD Information (Please print.)

\begin{tabular}{lc}
\hline Name \\
\hline Company (if applicable) \\
\hline Address (Street plus Apt or Ste) \\
\hline City \\
\hline Country \\
\hline Telephone \\
\hline E-Mail & Faxtal Code (9-digit ZIP for US) \\
\hline
\end{tabular}

NEW Information (Please print.)

\begin{tabular}{ll}
\hline Name \\
\hline Company (if applicable) \\
\hline Address (Street plus Apt or Ste) \\
\hline City & Postal Code (9-digit ZIP for US) \\
\hline Country & Fax \\
\hline Telephone & \\
\hline E-Mail &
\end{tabular}

